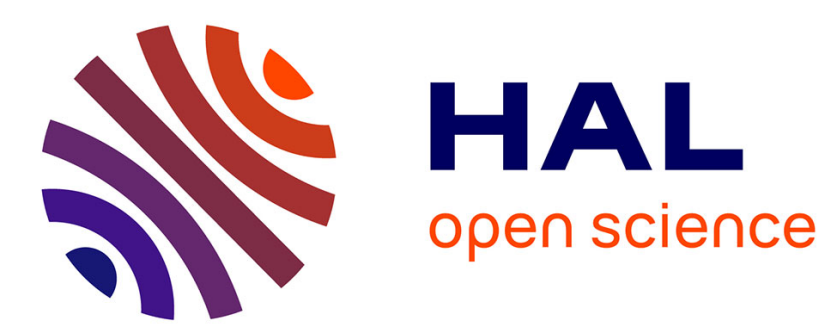

\title{
Electron and hole capture cross-sections at deep centers in gallium arsenide
}

\author{
A. Mitonneau, A. Mircea, G.M. Martin, D. Pons
}

\section{To cite this version:}

A. Mitonneau, A. Mircea, G.M. Martin, D. Pons. Electron and hole capture cross-sections at deep centers in gallium arsenide. Revue de Physique Appliquée, 1979, 14 (10), pp.853-861. 10.1051/rphysap:019790014010085300 . jpa-00244672

\section{HAL Id: jpa-00244672 https://hal.science/jpa-00244672}

Submitted on 1 Jan 1979

HAL is a multi-disciplinary open access archive for the deposit and dissemination of scientific research documents, whether they are published or not. The documents may come from teaching and research institutions in France or abroad, or from public or private research centers.
L'archive ouverte pluridisciplinaire HAL, est destinée au dépôt et à la diffusion de documents scientifiques de niveau recherche, publiés ou non, émanant des établissements d'enseignement et de recherche français ou étrangers, des laboratoires publics ou privés. 


\title{
Electron and hole capture cross-sections at deep centers in gallium arsenide
}

\author{
A. Mitonneau, A. Mircea, G. M. Martin and D. Pons \\ Laboratoires d'Electronique et de Physique Appliquée, 3, avenue Descartes, 94450 Limeil-Brevannes, France
}

(Reçu le 22 janvier 1979, révisé le 18 juin 1979, accepté le 20 juin 1979)

\begin{abstract}
Résumé. - Nous présentons une méthode, combinant l'excitation optique et le remplissage électrique de niveaux profonds, qui permet la mesure de la section de capture des pièges de minoritaires pour les porteurs majoritaires : par exemple $\sigma_{\mathrm{n}}$ pour un piège à trous dans un matériau de type $\mathrm{n}$. Cette méthode a été utilisée pour caractériser plusieurs centres profonds dans l'arseniure de gallium. Les résultats suivants ont été établis : le principal piège à électrons « EL 2 " n'est pas un tueur de durée de vie; le coefficient de température de l'énergie d'ionisation de plusieurs niveaux, y compris le niveau du chrome utilisé pour l'obtention des cristaux semi-isolants ; de très grandes $\left(10^{-15} \mathrm{~cm}^{2}\right.$ ou plus), et de très petites $\left(10^{-21} \mathrm{~cm}^{2}\right)$ sections de capture pour les électrons pour deux des niveaux étudiés; des mécanismes de capture envisageables sont mentionnés dans ces derniers cas.
\end{abstract}

\begin{abstract}
A method is presented, which combines optical excitation and electrical refilling of deep levels, allowing one to measure the majority carrier capture cross-section for minority carrier traps : e.g., $\sigma_{\mathrm{n}}$ for $a$ hole trap in n-type material. This method has been used to characterize many deep levels in gallium arsenide. The following results are obtained : the main electron trap « EL 2 » is not a hole lifetime killer ; the temperature coefficient of the ionization energy for several levels, including the $\mathrm{Cr}$ level used for compensation in semi-insulating crystals ; very large $\left(10^{-15} \mathrm{~cm}^{2}\right.$ or more), and very small $\left(10^{-21} \mathrm{~cm}^{2}\right)$ electron capture cross-sections for two of the levels ; possible capture mechanisms for these last cases are mentioned.
\end{abstract}

Introduction. - The increasing interest for the compound semiconductors, together with the refinement of the characterization methods, such as Deep Level Transient Spectroscopy [1] (D.L.T.S.), has led to a better knowledge of the many different deep levels which one can find in the forbidden band gap of the semiconductors. In the particular case of gallium arsenide numerous traps have been classified by several authors [2-6]; nevertheless, their origin is known only for a few of them which have been voluntarily introduced in the material during the growth [2] and then characterized. The influence of these traps on the optical and electrical properties of the semiconductor depends mainly on three characteristic properties of the level : its activation energy, concentration and capture cross-section for the free carriers. Some traps, such as the level due to the presence of chromium in the material, are very deep; they are then used for compensating the semiconductor in order to get the semi-insulating substrates needed for the realization of some devices. A detailed knowledge of their properties is then of first importance. Another important stimulus for the study of deep

$\left(^{*}\right)$ This work was partly supported by D.G.R.S.T. (Contract number 77-7-0085.) levels is the search for recombination centres responsible for the discrepancy [7] between the measured diffusion lengths and those expected in pure GaAs, and actually observed in the best L.P.E. crystals [8].

In this paper, many measured carrier capture crosssections are given for levels occurring in GaAs. The following informations may be deduced from these measurements : about the activation energy of the traps, the variation of the activation energy with temperature, the possible influence of the levels on the electrical and optical properties of the material and of the device, and finally about the capture mechanisms. We shall show in addition that the measurement of the capture cross-section is a way to separate levels for which the thermal emission rates are very similar at a given temperature.

In the following, we deal with many different levels appearing in gallium arsenide, and therefore in order to avoid confusions, we shall use the nomenclature given in references [3, 4 and 5] and just recall in brackets the label given by different authors.

1. Background. - In an effort to identify the capture mechanisms, C. H. Henry and D. V. Lang have studied in GaAs and $\mathrm{GaP}$ the variation of electron and hole capture cross-sections of some traps with 
temperature $[2,9]$. The studied levels are either unidentified traps arising in the as-grown material (HL 5 and HL 2 in L.P.E. layers and EL 2 in V.P.E. ones), or traps due to the presence of a given impurity in the material (mainly transition elements have been characterized : $\mathrm{Cu}, \mathrm{Fe}, \mathrm{Cr}$ ). They have found that both the order of magnitude and the variation of the electron capture cross-sections with temperature agree with a theory where multiphonon emission mechanism (M.P.E.) plays a leading role. Nevertheless, in the particular case of gallium arsenide none of the characterized traps appears to be able to really act as a recombination centre, that is to say, a centre having large capture cross-sections $\left(10^{-16} \mathrm{~cm}^{2}\right.$ or larger) for both free electrons and free holes. Indeed, the transition elements $\mathrm{Cr}, \mathrm{Fe}, \mathrm{Cu}$, have large $\sigma_{\mathrm{p}}$ values, but the $\sigma_{n}$ 's are small, in the $\left(10^{-19}, 10^{-20}\right) \mathrm{cm}^{2}$ range.

Nickel has been reported [7] to reduce the carrier lifetime, but as yet, a detailed electrical characterization of Ni-related deep levels has not been carried out.

Among the defects related to a given growth process, both $\sigma_{\mathrm{n}}$ and $\sigma_{\mathrm{p}}$ are known only for the traps HL 5 and HL 2 (respectively $A$ and $B$ in reference [2]) which are typical of L.P.E. material. Roughly speaking, the electron and hole capture cross-section for HL 2 are similar to those of the above mentioned transition elements, but the level HL 5 has an electron capture cross-section which is nearly 3 orders of magnitude larger at room temperature, so that, due to its hole capture cross-section [2] which is also very large $\left(10^{-15}\right.$ to $\left.10^{-14} \mathrm{~cm}^{2}\right)$, it could act in some cases as a recombination centre.

Nevertheless, the generally held view is that the best carrier lifetimes and diffusion lengths are obtained in L.P.E., and the worst one in melt grown material [10]. More effective recombination centres are then expected in this last material.

As a matter of fact, it is now well known that the upper half of the forbidden band-gap of GaAs can accommodate many different discrete levels which probably arise from various complex defects [11]. These levels are electron traps, characterized by relatively large values of their electron capture crosssection $\sigma_{n}$, and it would not be surprising if they had large $\sigma_{p}$ 's too since they are very deep. They exist mostly in melt grown material, have smaller concentrations in vapour phase epitaxy (V.P.E.) ones, and are entirely absent in liquid phase epitaxy (L.P.E.) layers. This may be correlated to the above mentioned variation of the diffusion lengths in these materials, and in fact, a tentative correlation was made recently [12] between the excess hole lifetime and the presence of a level which might be called the main electron trap of GaAs crystals, that is EL 2 ; this level also called 0 in many papers $[2,13]$, has been related to oxygen impurity in the past [14].

In part 2 , we describe the technique, based on
ODLTS [15], which has been used in order to determine the majority carrier capture cross-section for minority carrier traps (for instance $\sigma_{\mathrm{n}}$ for a hole trap in n-type material), and which can be applied to p-n junctions as well as to Schottky barriers. The way used to analyse the data is briefly described in the same paragraph. The results are given in part 3 . In part 3.1., we present the results obtained in as-grown material : $\sigma_{\mathrm{p}}$ for the electron trap EL 2 has been determined at $320 \mathrm{~K}$, and this is the first report of an experimental $\sigma_{\mathrm{p}}$ value for an electron trap in as-grown GaAs. The $\sigma_{\mathrm{n}}$ of this trap has been reported previously $[2,16]$; however, since more recent investigations [17] have shown that the data should have been analyzed more rigorously, we have found different and more accurate $\sigma_{n}$ figures up to very low temperatures. Both $\sigma_{\mathrm{n}}$ and $\sigma_{\mathrm{p}}$ have also been determined as a function of temperature for the chromium level. These results have already been published previously in the literature [2], but our data about $\sigma_{\mathrm{p}}$ for chromium are quite different. From the comparison of capture with emission results, we deduce a rough estimation of its temperature coefficient. Finally, three results of electron capture crosssections are given : two of them are the largest electron capture cross-sections which have ever been found in GaAs crystals, the third one shows that the corresponding level can act as an effective recombination centre. Part 3.2. is devoted to the study of traps arising in V.P.E. electron irradiated layers : the $\sigma_{\mathrm{p}}$ of one electron trap and four hole traps have been measured for the first time, three of them having never been reported as yet [18]. Part 4 is the conclusion.

2. Experimental. -2.1 PRINCIPLE OF OPERATION. - Our method combines the optical excitation and the electrical refilling of the traps : a short light pulse of high intensity is first sent on the sample, inducing the excitation of the traps. A OV bias pulse is then applied to the diode, inducing the refilling of the traps

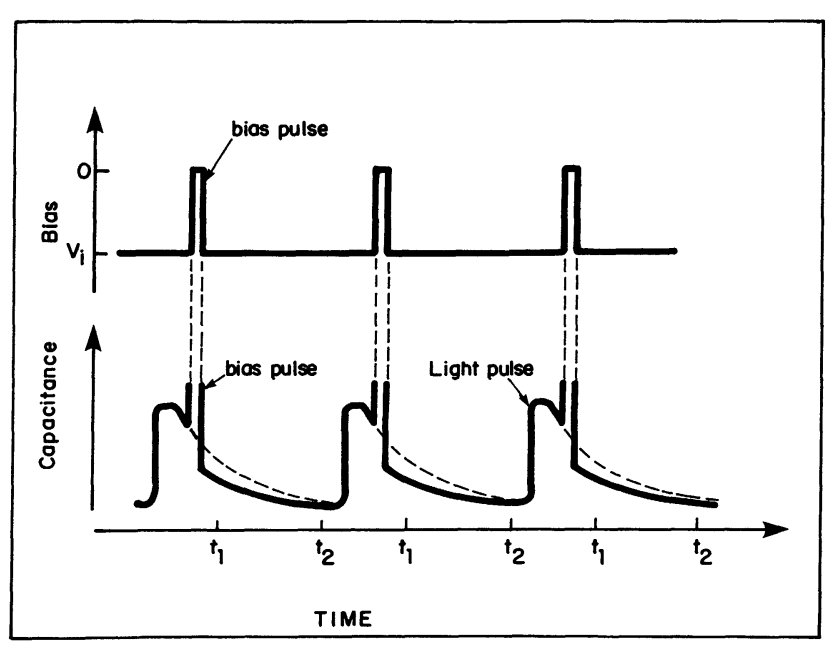

Fig. 1. - Timing of the sequence showing the capacitance variations during and after the light and bias pulses; the dashed lines indicate the capacitance variations without any bias pulse. 
with majority carriers. Figure 1 shows the timing of the sequence together with the capacitance variations of the sample; figure 2 is an example of resulting D.L.T.S. spectra obtained in varying the duration of the OV bias pulse.

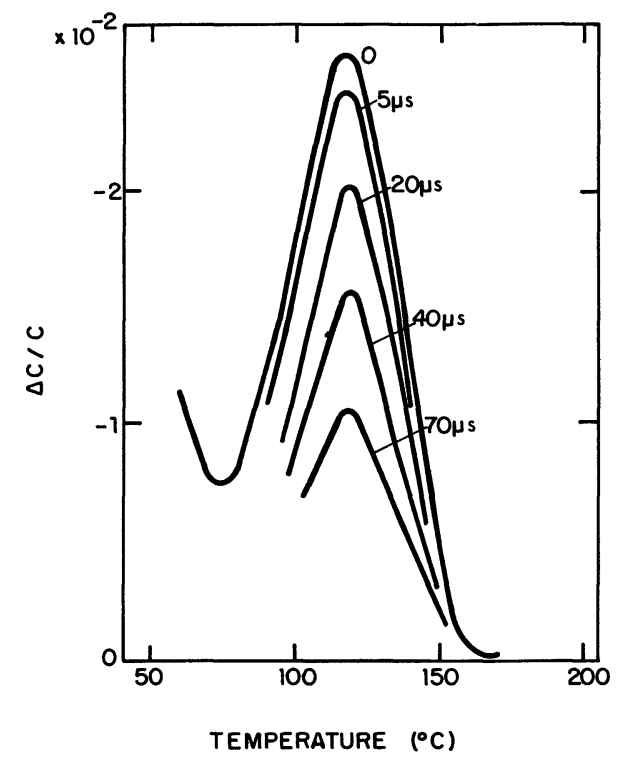

Fig. 2. - ODLTS spectra recorded on a Cr-doped n-type L.P.E. GaAs sample, for various values of the refilling OV bias pulse. Emission rate window : $0.88 \mathrm{~s}^{-1}$; reverse bias : $10 \mathrm{~V}$.

This method has the advantages of optical D.L.T.S. in that it allows an assessment of the minority carrier traps in Schottky barriers as well as in p-n junctions ; in addition, the optical excitation of the traps with sub-band-gap light ensures an uniform refilling of the traps in the whole depleted layer, which is seldom the case, when electrical injection is used with asymetrical $p^{+}-n$ junctions. Finally, it allows a precise

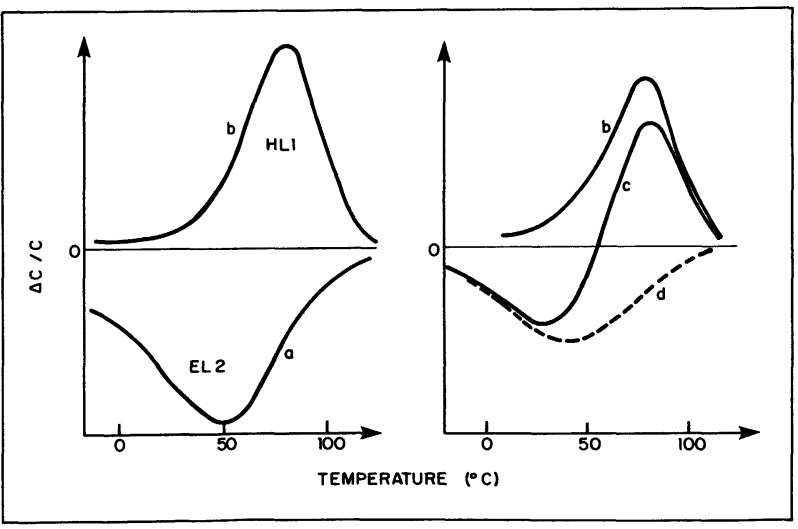

Fig. 3. - D.L.T.S. spectra recorded on a chromium doped p-type $\left(p=1.10^{17} \mathrm{~cm}^{-3}\right)$ bulk GaAs sample. The emission rate window is $0.88 \mathrm{~s}^{-1}$ and the reverse bias $4 \mathrm{~V}$. Positive peaks are due to majority carrier traps and negative peaks to minority carrier ones. Curve (a) is obtained with optical excitation alone, curve (b) with electrical one alone, and curve (c) when combining both. Curve (d) is obtained in substracting (b) from (c) and then includes only the contribution of EL 2. determination of the cross-sections for the carriers, even in the complex case where the peaks due to several traps are partly mixed ; figure 3 is such an example in p-type material, where the negative peak due to EL 2 is partly superimposed to the positive peak due to the chromium level HL 1 : curve (a) is obtained with the light pulses applied alone, curve (b) with a 200 ns bias pulse applied alone, and curve (c) is obtained when the same bias pulse is applied after the light pulse. The negative peak of spectrum (a) is mainly due to EL 2, the (positive) peak of spectrum (b) is due to HL 1. Spectrum (c) includes contributions from both HL 1 and EL 2; however, this difficulty is overcome by substracting curve (b) from curve (c). In this way we get the differential spectrum (d) in which the HL 1 contribution has been eliminated. From the dependence of the peak height (curve (d)) versus bias pulse duration, the $\sigma_{\mathrm{p}}$ of EL 2 can be determined. For the majority carrier traps crosssection measurements, the same technique as to the one described by D. V. Lang in reference [1] has been used.

2.2 EXPERIMENTAL SET-UP. - Our set-up, based on the use of a programmable calculator has already been described [19]. For the capacitance measurements, we use a Boonton 72 B capacitance meter; however, in order to be able to apply very short and clean bias pulses, we devised a special arrangement using reed relays which connect the sample alternatively to the capacitance meter and to a pulse generator. The pulse generator has a d.c. offset which is exactly equal to the reverse bias applied through the capacitance meter. Switching the sample from the capacitance meter to the pulse generator, and vice-versa, is controlled by the calculator and follows the closebefore-open principle, so that the sample sees the same reverse bias all the time, except during the bias pulses when it goes to zero. The timing of the whole sequence is repetitively generated by the calculator.

2.3 Results ANALYSIS. - The use of a YAG laser of about $200 \mathrm{~mW}$ at $1.06 \mu$ to get the light pulse allows us to reach the saturation in a few $\mathrm{ms}$; a given level is then filled according to the ratio : $e_{\mathrm{n}}^{0} /\left(e_{\mathrm{n}}^{0}+e_{\mathrm{p}}^{0}\right)$, where $e_{\mathrm{n}}^{0}\left(e_{\mathrm{p}}^{0}\right)$ is the optical emission rate toward the conduction (valence) band.

During the OV bias pulse, the traps refill with majority carriers with a time constant

$$
\tau=\left(n \sigma_{\mathrm{n}}\langle v\rangle\right)^{-1}
$$

in n-type material $\left(\tau=\left(p \sigma_{\mathrm{p}}\langle v\rangle\right)^{-1}\right.$ in p-type material), where $n(p)$ is the doping level, $\sigma_{\mathrm{n}}\left(\sigma_{\mathrm{p}}\right)$ the electron (hole) capture cross-section of the traps for the carriers, $\langle v\rangle$ the mean square thermal velocity of the carriers. From the slope of the variation of the D.L.T.S. peak height with the bias pulse duration, we deduce $\sigma$.

It has been shown, recently [17], that special care must be devoted to the analysis of the carrier capture 


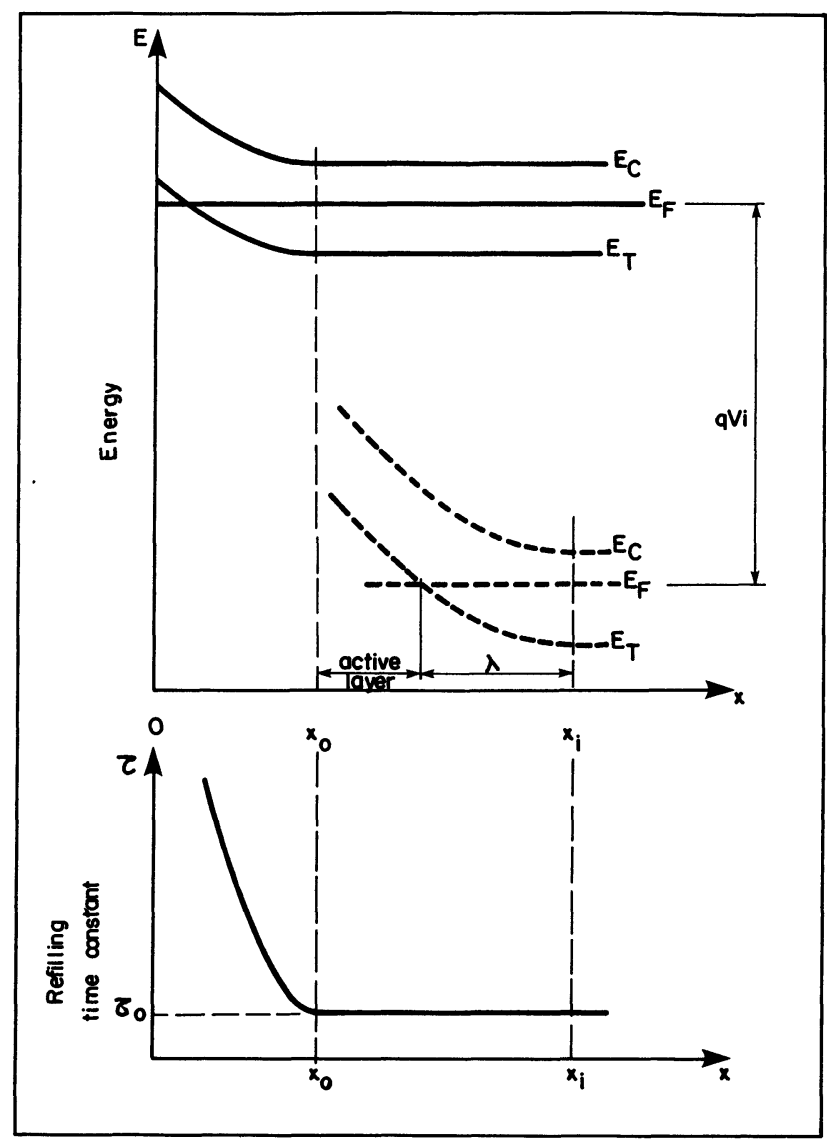

Fig. 4. - Schematic band diagramm showing the part of the depleted layer where the majority carrier traps are filled and empty alternatively (active layer), together with the refilling time constant as a function of the distance $x$ from the barrier.

cross-sections data. This is mainly due to a zone band edge $\lambda$, and to a remaining depleted layer $x_{0}$ during the refilling bias pulse (Fig. 4); inside $\lambda$, the majority carriers traps never empty, and inside $x_{0}$, their refilling time constant varies exponentially with $\left(x_{0}-x\right)^{2}$.

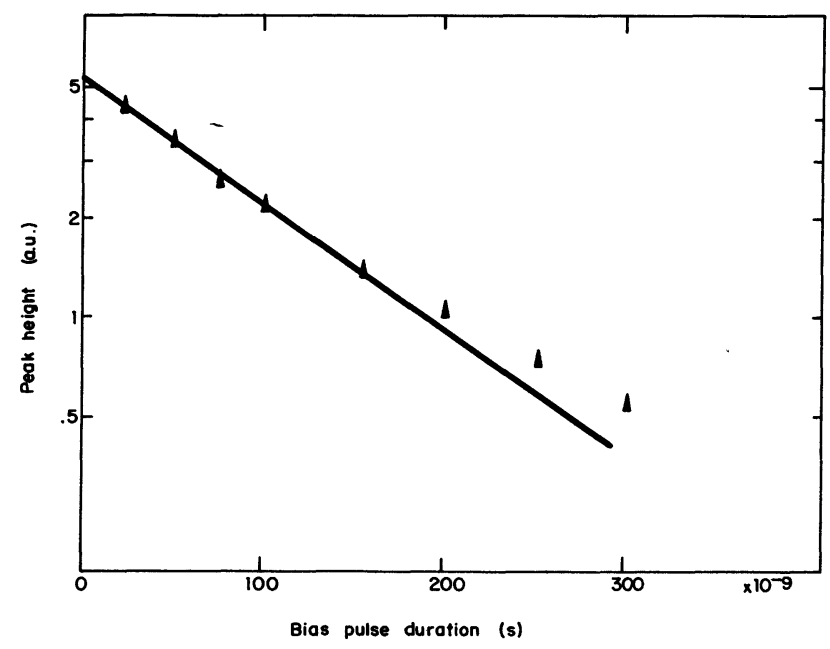

Fig. 5. - Peak height versus bias pulse duration for the hole trap due to the chromium level in p-type material. $p=1 \times 10^{16} \mathrm{~cm}^{-3}$; $T=356 \mathrm{~K} ; V=-10 \mathrm{~V}$.
We have therefore used a reverse bias as large as possible ( $10 \mathrm{~V}$ in most cases) in order to minimize these effects, and the value of $\sigma$ was deduced using only the first points which are aligned (Fig. 5). (They generally represent at least $50 \%$ of the whole amplitude of the signal.) It is worth noting that, in the case of a minority carrier trap (e.g. a hole trap in n-type material), at the edge of the depleted layer, the electrons (or holes) recombine with the trapped holes (electrons). The thickness of the layer involved : $\lambda_{\min }$, depends on both $n$ and $\sigma_{\mathrm{n}}$ (or $p$ and $\sigma_{\mathrm{p}}$ ) and may then be small in some cases since we are concerned with a minority carrier trap. A good fit with the exponential law can therefore be obtained in that case, since the contribution of the traps inside $x_{0}$ to the capacitance variation, varying as $x . \mathrm{d} x$, is small.

Figure 6 is such an example, obtained for the hole trap due to the chromium level in n-type material showing the nearly ideal exponential variation of the refilling rate as a function of the $\mathrm{OV}$ bias pulse duration.

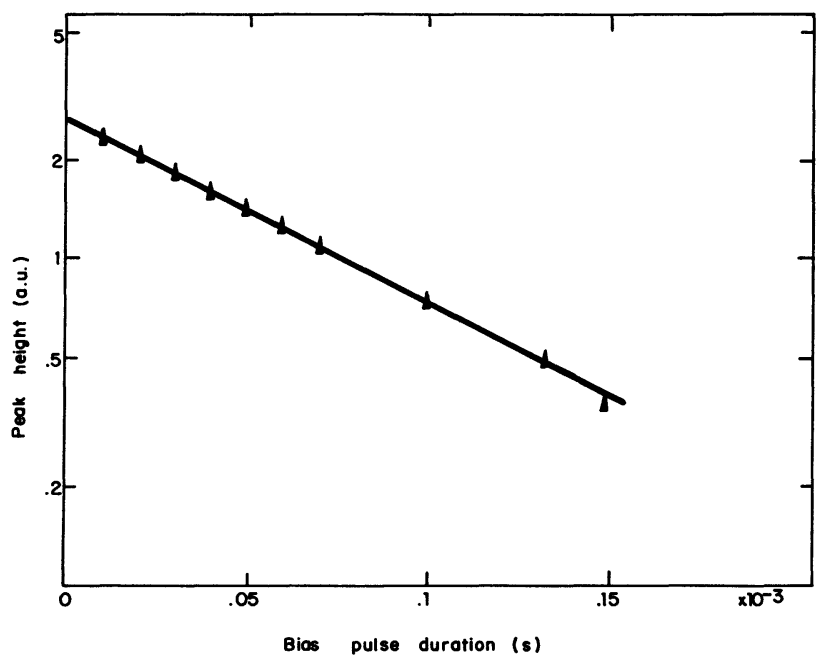

Fig. 6. - Peak height versus bias pulse duration in the case of a minority carrier trap : the chromium level in n-type material. Bias $V_{\mathrm{i}}=10 \mathrm{~V} ; T=393 \mathrm{~K} ; n=6.2 \times 10^{14} \mathrm{~cm}^{-3}$.

These features : uniform refilling inside the depleted layer, reverse bias as large as possible, measurement of the refilling time constant using only the first points aligned, are of first importance for the accuracy of the results. Given our experimental conditions, an uncertainty by about a factor of 2 can be accounted in most cases for the values of $\sigma$ given in the present work.

The range of capture cross-sections that we can measure depends on the doping level of the material and on the value of the shortest pulse which can be applied to the sample (about $30 \mathrm{~ns}$ in our case). For example, with a carrier concentration of $1 \times 10^{15} \mathrm{~cm}^{-3}$, we are able to measure capture cross-sections as large as about $5 \times 10^{-16} \mathrm{~cm}^{2}$. 
The minority carrier traps that can be assessed using the optical method are only those which give rise to a peak in the O.D.L.T.S. spectrum : the ratio $e_{\mathrm{n}}^{0} /\left(e_{\mathrm{n}}^{0}+e_{\mathrm{p}}^{0}\right)$ must not be too small, as it is the case for example for the iron level [3].

It has been shown [20] that, assuming a linear dependence of the ionization energy $E_{\mathrm{i}}$ of a bound state with the temperature : $E_{\mathrm{i}}=E_{\mathrm{i}}-\alpha T$, the temperature coefficient $\alpha$ may be deduced from the knowledge of emission rate data $: e_{n}$, together with the variation of the capture cross-section $\sigma$ with the temperature. If we assume for the latter an exponential dependence with $1 / T$ :

$$
\sigma=\sigma_{\infty} \exp \left(-\frac{E_{\mathrm{B}}}{k T}\right),
$$

$e_{\mathrm{n}}$ can be written :

$$
e_{\mathrm{n}}=\gamma T^{2} \sigma_{\infty} \exp \frac{\alpha^{\prime}}{k} \exp \left(-\frac{E_{\mathrm{i}}+E_{\mathrm{B}}}{k T}\right)
$$

where $k$ is the Boltzmann constant and $\gamma$ a numerical constant depending on the effective density of states in the conduction or valence band, and on the effective mass of the carriers.

Emission rate measurements yield $\left(E_{\mathrm{i}}+E_{\mathrm{B}}\right)$ together with $\left(\sigma_{\infty} \exp \alpha^{\prime} / k\right)$. Capture cross-section measurements yield $E_{\mathrm{B}}$ and $\sigma_{\infty}$. The temperature coefficient $\alpha$ may then be deduced from these complementary measurements, and it will be given below for some of the studied traps. We recall that $\alpha_{\mathrm{n}}^{\prime}=\alpha_{\mathrm{n}}+k \ln g$ for electron traps, and that $\alpha_{\mathrm{p}}^{\prime}=\alpha_{\mathrm{p}}-k \ln g$ for hole traps, $g$ being the degeneracy factor of the trap.

3. Results. - 3.1 As-Grown MATERial. - 3.1.1 EL 2. - In order to obtain an estimation of the influence of the trap EL 2 on the properties of the crystal, we have used the above method to determine its hole capture cross-section; p-type bulk material $\left(p=1 \times 10^{17} \mathrm{~cm}^{-3}\right)$ has been assessed; an $n^{+}$ epitaxial layer of about $2 \mu$ was deposited to get a diode. At the temperature $T=320 \mathrm{~K}$, the hole capture time constant we found is about $180 \mathrm{~ns}$, which leads to the value $\sigma_{\mathrm{p}}=2 \times 10^{-18} \mathrm{~cm}^{2}$. The minority carrier lifetime $\tau_{\mathrm{p}}$, in the case where it is governed by a recombination centre, is given by the relationship : $1 / \tau_{\mathrm{p}}=C_{\mathrm{p}} n_{T}$. If we introduce the measured value of $C_{\mathrm{p}}=\sigma_{\mathrm{p}}\langle v\rangle$, as the minority carrier lifetime is $2 \times 10^{-8} \mathrm{~s}$ or less, in pure n-type GaAs [10], the recombination due to EL 2 would become important if its concentration was larger than $10^{18} \mathrm{~cm}^{-3}$. Such a high concentration of traps has never been observed in as-grown GaAs crystals, and we can then conclude that the suggested correlation between the concentration of the trap EL 2, and the minority carrier diffusion length in reference [12] is accidental and that the level EL 2 doesn't affect the hole diffusion length in $n$-type gallium arsenide.
The electron capture cross-section of the trap EL 2 has been determined as a function of temperature from $273 \mathrm{~K}$ to $52 \mathrm{~K}$. As pointed out before, special care has been taken to avoid erroneous measurements : we used a Schottky barrier (gold evaporated) made on a low doped sample $\left(n=1.3 \times 10^{15} \mathrm{~cm}^{-3}\right)$ and the applied bias was $10 \mathrm{~V}$. Only the trap EL 2 was present in this sample. The values of $\sigma_{\mathrm{n}}$ deduced of our measurements are therefore expected to be more reliable than previously published one $[2,17]$, and they extend the temperature range until $50 \mathrm{~K}$. They are intermediate between the values of reference [ 2 and 17], but we find also that they are thermally activated until about $80 \mathrm{~K}$ with an activation energy

$$
E_{\mathrm{B}}=0.066 \mathrm{eV}
$$

and a preexponential factor $\sigma_{\infty}=6 \times 10^{-15} \mathrm{~cm}^{2}$. This result is displayed graphically on figure 7 . Our values for $\sigma_{\infty}$ and $E_{\mathrm{B}}$ are slightly different of those given in the literature [2]. Emission rate measurements yield for $\sigma_{\infty} \exp \alpha^{\prime} / k=8.8 \times 10^{-14} \mathrm{~cm}^{2}$, and we can therefore deduce : $\alpha=2.9 \times 10^{-4} \mathrm{eV} \mathrm{K}^{-1}$ (taking $g_{\mathrm{n}}=1 / 2$ as suggested in [20]).

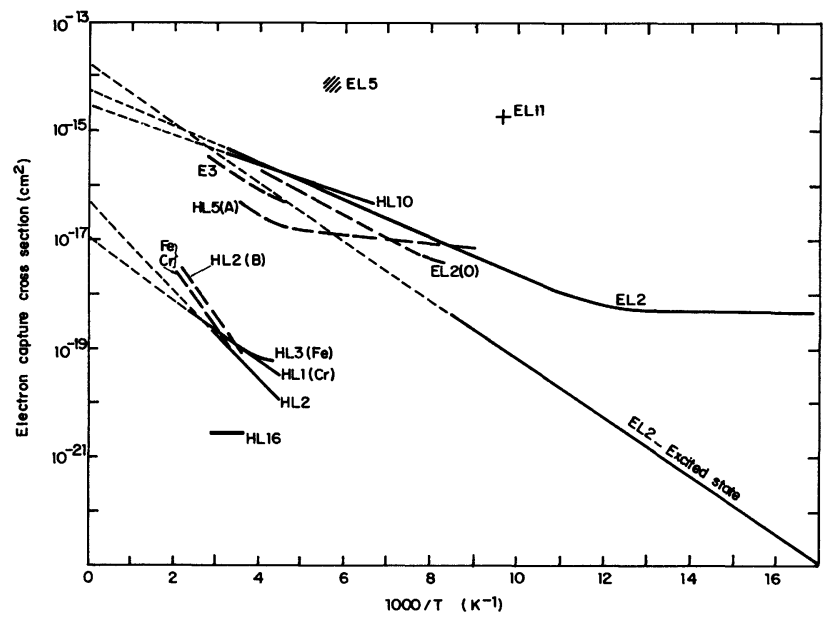

Fig. 7. - Electron capture cross-section as a function of temperature for the studied levels. The dotted curves are Lang's results (ref. [2] and [9]). Also mentionned is the EL 2's excited state capture cross-section (ref. [24]).

3.1.2 Chromium. - The electron and hole capture cross-sections have also been determined for the chromium related level HL 1 as a function of temperature and are quite different of those reported in the literature [2]. An important point is that we have not been able, using DLTS or ODLTS, to detect any electron trap, having a concentration of the same order of magnitude than HL 1 , in the chromium doped layers, whether they are n- or p-type, and whether they are bulk, V.P.E. or L.P.E. ones : we always find for chromium a single hole trap at about $0.9 \mathrm{eV}$. Its electron capture cross-section is thermally activated with a slope $E_{g}=0.117 \mathrm{eV}$ and a preexpo- 
nential factor $\sigma_{\infty}=1.3 \times 10^{-17} \mathrm{~cm}^{2}$ (Fig. 7). For the hole capture cross-section, we find that $\sigma_{\mathrm{p}}$ is slightly increasing above room temperature, leading to $\sigma_{\infty}=1 \times 10^{-16} \mathrm{~cm}^{2}$ (see Fig. 8). The temperature coefficient of the chromium level can thus be estimated to be about : $\alpha=5.2 \times 10^{-4} \mathrm{eV} \mathrm{K}^{-1}$, which is nearly the temperature coefficient of the GaAs bandgap. The important conclusion is then that the chromium related trap is pinned to the conduction band.

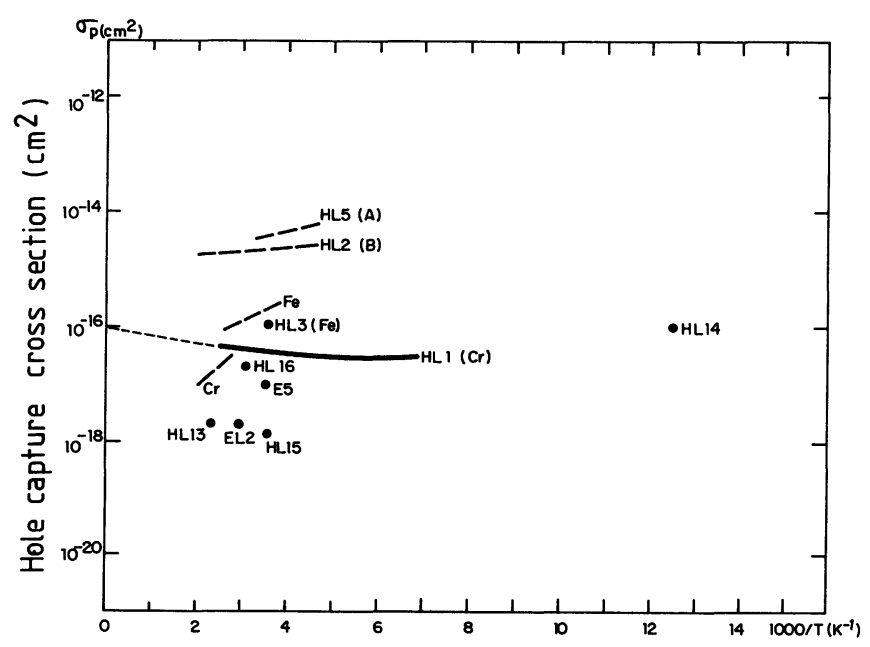

Fig. 8. - Hole capture cross-section as a function of temperature for the studied levels. The dotted curves are Lang's results (ref. [2] and [9]).

3.1.3 Other levels. - Iron has been observed to be a systematic contaminant of V.P.E. layers; the values we find for the activation energy of its level HL 3 in the band-gap scatter from sample to sample from $\left(E_{\mathrm{v}}+0.56\right) \mathrm{eV}$ to $\left(E_{\mathrm{v}}+0.59\right) \mathrm{eV}$. The electron and hole capture cross-section we measure for its level are not very far from the values given in ref. [2] (Figs 7 and 8), although the activation energy we find for $\sigma_{\mathrm{n}}$ is smaller.

Finally, three electron capture cross-sections have been measured : those of the traps HL 10 [3], EL 5 and EL 11 [4], which exhibit very large $\sigma_{\mathrm{n}}$ values : HL 10 is a hole trap lying near the mid-band gap and we find that it has a thermally activated electron capture cross-section with an activation energy $E_{\mathrm{B}}=0.054 \mathrm{eV}$ and a preexponential factor $\sigma_{\infty}=3 \times 10^{-15} \mathrm{~cm}^{2}$, so that its $\sigma_{\mathrm{n}}$ at room temperature is as large as $4 \times 10^{-16} \mathrm{~cm}^{2}$. Nevertheless, this trap acts as a hole trap, and D.L.T.S. data yield $E_{\mathrm{i}}=0.83 \mathrm{eV}$ and $\sigma_{\infty} \exp \alpha^{\prime} / k=1.7 \times 10^{-13} \mathrm{~cm}^{2}$. Hence the lower limit of its $\sigma_{\mathrm{p}}$ can be estimated, assuming that it does not vary with temperature (which is the case for most of the studied hole traps) and that $\alpha$ is the same for this trap that for the band gap (which is the largest reasonable value); we find :

$$
\sigma_{\mathrm{p}} \geqslant 5 \times 10^{-16} \mathrm{~cm}^{2} .
$$

It appears then that this trap could be in some cases an effective recombination centre, in view of the large values of its $\sigma_{\mathrm{n}}$ and $\sigma_{\mathrm{p}}$.

The electron capture cross-section of EL 5 and EL 11 have been assessed in a low doped material ( $n=1.2 \times 10^{14} \mathrm{~cm}^{-3}$ ) using a Schottky barrier (gold evaporated), but we have been able to really determine $\sigma_{\mathrm{n}}$ only for EL $11: \sigma_{\mathrm{n}}=2 \times 10^{-15} \mathrm{~cm}^{2}$ at $T=100 \mathrm{~K}$, since essentially no change in the peak height of EL 5 occurred with pulses as short as $50 \mathrm{~ns}$. We can therefore estimate its $\sigma_{\mathrm{n}}$ to be larger than $5 \times 10^{-15} \mathrm{~cm}^{2}$ at $T=200 \mathrm{~K}$, which is the largest value ever observed for an electron trap in GaAs crystals. The result for EL 11 is striking because the $\sigma_{\mathrm{n}}$ we measured is larger than the value deduced from emission rate measurements :

$$
\sigma_{\infty} \exp \frac{\alpha^{\prime}}{k}=3 \times 10^{-16} \mathrm{~cm}^{2}
$$

and it follows that either $\sigma_{\mathrm{n}}$ decreases with increasing temperature, or that the temperature coefficient of this trap is negative : in that case, assuming that $\sigma_{\mathrm{n}}$ is constant with temperature, we find

$$
E_{T}=\left(0.17+1.6 \times 10^{-4} \mathrm{~T}\right) \mathrm{eV} .
$$

At the opposite, the value of $\sigma_{\infty} \exp \alpha^{\prime} / k$ calculated for EL 5 is about $10^{-13} \mathrm{~cm}^{2}$ : the level probably has a zero temperature coefficient and it follows the conduction band. This trap is definitively not the same as the level E 3 as previously suggested [4]; the latter, created by electron irradiation is attributed by D. V. Lang to a Ga vacancy [21] and has a much smaller electron capture cross-section $\left(1 \times 10^{-16} \mathrm{~cm}^{2}\right)$ at the same temperature.

\subsection{EleCtron IRRADIATED MATERIAL. - Electron} irradiation at room temperature gives rise in L.P.E. GaAs to a number of traps, which have been studied and classified by D. V. Lang [21]. Mainly five electron traps, labelled E 1 to E 5, and one hole trap $\mathrm{H} 1$ have been reported as yet. Electron irradiation defects are also studied in our laboratory [22], in V.P.E. or bulk material; in addition to the levels studied by D.V. Lang, we find some new ones which are likely to be related to the presence of impurities in the layers. They are labelled HL $13\left(E_{\mathrm{v}}+0.96 \mathrm{eV}\right)$, HL 14 $\left(E_{\mathrm{v}}+0.25 \mathrm{eV}\right)$, which is the same as $\mathrm{H} 1, \mathrm{HL} 15$ $\left(E_{\mathrm{v}}+0.56 \mathrm{eV}\right)$ and HL $16\left(E_{\mathrm{v}}+0.79 \mathrm{eV}\right)$. Figure 9 is a typical example of a D.L.T.S. spectrum recorded on a p-type V.P.E. layer annealed at $200^{\circ} \mathrm{C}$ for $6 \mathrm{~min}$., after having been irradiated with $1 \mathrm{MeV}$ electrons at a dose of $3 \times 10^{16} \mathrm{~cm}^{2}$. We clearly observe the new hole traps HL 13, HL 15, HL 16, and it must be noticed that HL 16 appears at the same temperature as the level HL 2 [3] characteristic of L.P.E. as-grown layers, and that HL 15 appears at the same temperature as $\mathrm{HL} 3$ often detected in V.P.E. layers. 


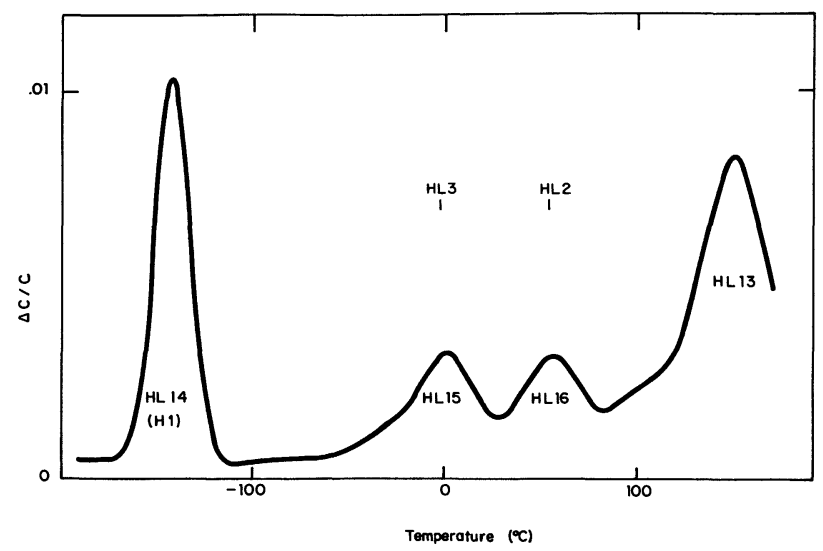

Fig. 9. - D.L.T.S. spectra recorded on a p-type $\left(p=7 \times 10^{15} \mathrm{~cm}^{-3}\right)$ V.P.E. layer irradiated at a dose $3 \times 10^{16} \mathrm{~cm}^{2}$ with $1 \mathrm{MeV}$ electrons and annealed at $200^{\circ} \mathrm{C}$ for $6 \mathrm{~min}$. The emission rate window is $7.5 \mathrm{~s}^{-1}$. The position of the peaks due to HL 2 (B) and HL 3 are also indicated.

The electron capture cross-section of HL 16 has been measured in a n-type layer $\left(n=2.1 \times 10^{16} \mathrm{~cm}^{-3}\right)$, irradiated in a modified Van De Graaf accelerator with $1 \mathrm{MeV}$ electrons at a dose $7 \times 10^{15} \mathrm{~cm}^{2}$. The sample has been then annealed at $300^{\circ} \mathrm{C}$ for $15 \mathrm{~min}$. in order to get rid of some of the other levels which were also created by the electron irradiation. The electron refilling time constant has been found to be almost constant from $290 \mathrm{~K}$ to $335 \mathrm{~K}$, leading to $\sigma_{\mathrm{n}}=3 \times 10^{-21} \mathrm{~cm}^{2}$ : this suggests that M.P.E. [9] doesn't play an important role in the capture process, as it is the case for the level HL 2 (see Fig. 7), and the cross-section is appreciably lower at the same temperature : HL 16 is then different from the level HL 2 (labelled « B " in (1)) at $E_{\mathrm{v}}+0.71 \mathrm{eV}$ which is found in as-grown L.P.E. layers. This is corroborated by the measurement of $\sigma_{\mathrm{p}}$ for this trap as shown below. The hole capture cross-sections have been measured in p-type, $\mathrm{Zn}$ doped, V.P.E. layers with a doping level around $1.7 \times 10^{16} \mathrm{~cm}^{-3}$; for the traps E 5, HL 14 and HL 16, the electron irradiation dose at $1 \mathrm{MeV}$ was $8 \times 10^{15} \mathrm{~cm}^{-2}$, and the respective $\sigma_{\mathrm{p}}$ 's are given in table I. The hole capture cross-section for HL 16 is 2 orders of magnitude lower than for the level HL 2, and they cannot be confused any more. The E 5's $\sigma_{\mathrm{p}}$ is quite large for an electron trap, but certainly not enough for making it a lifetime killer, whereas the hole capture cross-section of HL 14, equal to $1 \times 10^{-16} \mathrm{~cm}^{2}$, could make this trap a lifetime killer in n-type material if introduced in sufficiently large concentration.

The trap HL 15 has its D.L.T.S. emission peak at nearly the same temperature as HL 3 , but its $\sigma_{\mathrm{p}}$ is two orders of magnitude lower. Figure 10 gives the spectra obtained with two different durations of the refilling bias pulse : the shoulder observed on the low temperature side of the peak is due to an additional unidentified trap.

Finally, special mention must be devoted to the trap HL 13 which is the deepest trap ever found in gallium arsenide : D.L.T.S. measurements yield for HL $13: E_{\mathrm{i}}=0.96 \mathrm{eV}, \sigma_{\infty} \exp \alpha^{\prime} / k=6.7 \times 10^{-15} \mathrm{~cm}^{2}$, and we have measured at

$$
T=420 \mathrm{~K}, \quad \sigma_{\mathrm{p}}=1.5 \times 10^{-18} \mathrm{~cm}^{2} .
$$

In spite of this low value for $\sigma_{\mathrm{p}}$ and of the depth of the trap in the band-gap, it acts as a hole trap : its $\sigma_{\mathrm{n}}$

TABLE I

\begin{tabular}{|c|c|c|c|c|c|c|}
\hline Trap & $\begin{array}{l}\text { Temperature } \\
\text { range }\end{array}$ & $\begin{array}{l}\text { Electron capture } \\
\text { cross-section }\left(\mathrm{cm}^{2}\right)\end{array}$ & $\begin{array}{l}\text { Hole capture } \\
\text { cross-section } \\
\left(\mathrm{cm}^{2}\right) \\
-\end{array}$ & $\begin{array}{c}\text { Material assessed } \\
\quad-\end{array}$ & $\begin{array}{l}\text { Activ } \\
\text { energy at } 0 \mathrm{~K}\end{array}$ & Ref. \\
\hline EL 2 & $\begin{array}{l}50 \mathrm{~K} \text { to } 273 \mathrm{~K} \\
320 \mathrm{~K}\end{array}$ & $\sigma_{\mathrm{n}}=6 \times 10^{-15} \exp \left(\frac{-0.066}{k T}\right)$ & $\sigma_{p}=2 \times 10^{-18}$ & $\begin{array}{l}\text { Undoped n-type VPE } \\
\text { p-type bulk material }\end{array}$ & $E_{\mathrm{c}}-0.82 \mathrm{eV}$ & [4] \\
\hline $\begin{array}{l}\text { HL } 1 \\
\text { (chromium) }\end{array}$ & $\begin{array}{l}230 \mathrm{~K} \text { to } 390 \mathrm{~K} \\
150 \mathrm{~K} \text { to } 370 \mathrm{~K}\end{array}$ & $\sigma_{\mathrm{n}}=10^{-17} \exp \left(\frac{-0.115}{k T}\right)$ & $\sigma_{\mathrm{p}}=5 \times 10^{-17}$ & $\begin{array}{l}\text { n-type L.P.E. } \\
\text { p-type L.P.E. }\end{array}$ & $E_{\mathrm{v}}+0.89 \mathrm{eV}$ & [3] \\
\hline $\begin{array}{l}\mathrm{HL} 3 \\
\text { (iron) }\end{array}$ & $250 \mathrm{~K}$ & $\sigma_{\mathrm{n}}=(6-7.5) 10^{-20}$ & $\sigma_{\mathrm{p}}=9.2 \times 10^{-17}$ & $\begin{array}{l}\text { Undoped p-type V.P.E. } \\
\text { Iron diffused V.P.E. }\end{array}$ & $E_{\mathrm{v}}+0.59 \mathrm{eV}$ & [3] \\
\hline HL 10 & $150 \mathrm{~K}$ to $300 \mathrm{~K}$ & $\sigma_{\mathrm{n}}=3 \times 10^{-15} \exp \left(\frac{-0.054}{k T}\right)$ & $\sigma_{\mathrm{p}}=5 \times 10^{-16}$ & Undoped n-type V.P.E. & $E_{\mathrm{v}}+0.83 \mathrm{eV}$ & [3] \\
\hline EL 5 & $200 \mathrm{~K}$ & $\sigma_{\mathrm{n}}=5 \times 10^{-15}$ & & Undoped n-type V.P.E. & $E_{\mathrm{c}}-0.42 \mathrm{eV}$ & [4] \\
\hline EL 11 & $100 \mathrm{~K}$ & $\sigma_{\mathrm{n}}=2 \times 10^{-15}$ & & Undoped n-type V.P.E. & $E_{\mathrm{c}}-0.17 \mathrm{eV}$ & [4] \\
\hline HL 16 & $\begin{array}{l}290 \mathrm{~K} \text { to } 335 \mathrm{~K} \\
313 \mathrm{~K}\end{array}$ & $\sigma_{\mathrm{n}}=3 \times 10^{-21}$ & $\sigma_{\mathrm{p}}=2 \times 10^{-17}$ & $\begin{array}{l}\text { Zn doped p-type V.P.E. } \\
\text { irradiated with } 1 \mathrm{MeV} \mathrm{e}^{-}\end{array}$ & $E_{\mathrm{v}}+0.79 \mathrm{eV}$ & {$[18,5]$} \\
\hline E 5 & $278 \mathrm{~K}$ & & $\sigma_{\mathrm{p}}=1 \times 10^{-17}$ & - & $E_{\mathrm{c}}-0.83 \mathrm{eV}$ & [21] \\
\hline HL 14 & $80 \mathrm{~K}$ & & $\sigma_{\mathrm{p}}=1 \times 10^{-16}$ & - & $E_{\mathrm{v}}+0.25 \mathrm{eV}$ & {$[18,5]$} \\
\hline HL 15 & $280 \mathrm{~K}$ & & $\sigma_{\mathrm{p}}=1.4 \times 10^{-18}$ & - & $E_{\mathrm{v}}+0.56 \mathrm{eV}$ & {$[18,5]$} \\
\hline HL 13 & $400 \mathrm{~K}$ & & $\sigma_{\mathrm{p}}=2 \times 10^{-18}$ & - & $E_{\mathrm{v}}+0.96 \mathrm{eV}$ & {$[18,5]$} \\
\hline
\end{tabular}




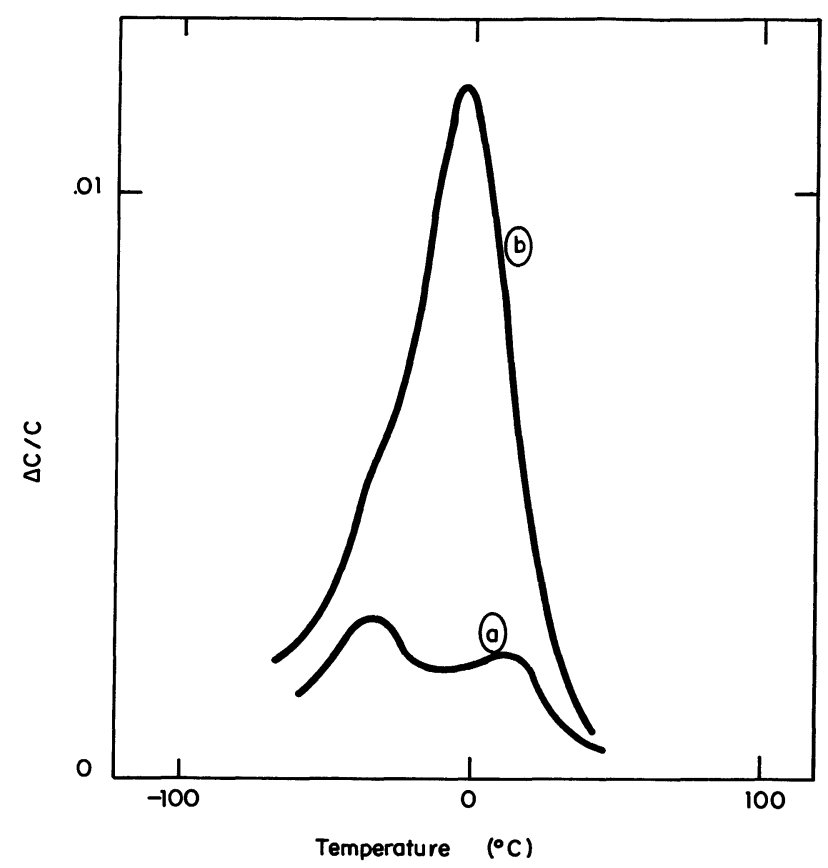

Fig. 10. - D.L.T.S. spectra recorded on an irradiated p-type V.P.E. layer using two different durations of the refilling bias pulse : $0.5 \mu$ s for curve (a) and $10 \mu$ s for curve (b). Two different peaks are clearly resolved in the case of the short duration bias pulse. Emission rate window : $5.5 \mathrm{~s}^{-1}$, reverse bias : $10 \mathrm{~V}$.

must then be extremely low, and in fact, if we do the same calculation as for HL 10 , we find

$$
\sigma_{\mathrm{n}} \leqslant 5 \times 10^{-19} \mathrm{~cm}^{2}
$$

as for HL 16, it would be interesting in that case to search for Auger effect.

4. Conclusion. - The measured capture crosssections are summarized in table $I$, and displayed graphically on figures 7 and 8 . The presented method for the measurement of $\sigma_{n}$ in n-type material (or of $\sigma_{\mathrm{p}}$ in p-type material) for the minority carrier traps, combining optical and electrical refilling of the traps, has allowed us to determine the minority carrier cross-section of six levels appearing either in as-grown or in $1 \mathrm{MeV}$ electron irradiated V.P.E. GaAs. Among all the levels which have been characterized in gallium arsenide, only some of them are expected to have an undesirable influence on device operation, and we have tried to identify them : the most common trap of GaAs : El 2 appears to be harmless, but the hole trap $\mathrm{HL} \mathrm{10,} \mathrm{due} \mathrm{to} \mathrm{its} \mathrm{large}$ electron and hole capture cross-sections, could be in most cases an effective recombination centre. In addition, special attention must be devoted to the traps EL 5 and EL 11, for which the electron capture cross-sections are already very large at low temperature.

Electron and hole capture cross-section measurements have appeared to be a good way to separate levels which have almost the same activation energy : the level HL 15 created in V.P.E. GaAs by $1 \mathrm{MeV}$ 'electron irradiation is different from the iron level HL 3 which has nearly the same thermal emission rate, but a larger $\sigma_{\mathrm{p}}$; in the same way, the hole trap HL 16 created in $1 \mathrm{MeV}$ V.P.E. or L.P.E. irradiated $\mathrm{GaAs}$, is different from the level HL 2 at $E_{\mathrm{v}}+0.71 \mathrm{eV}$ which is typical of L.P.E. layers.

Our results about the hole capture cross-section of the chromium level show clearly that it does not vary with temperature and also that this level is pinned to the conduction band whereas it is a hole trap ; this determination of its position in the band gap as a function of temperature is of first importance for the understanding of the properties of the semiinsulating substrates.

Finally, about the capture process, for at least three of the studied electron capture cross-sections, the value of $\sigma_{n}$ or its variation with temperature are not typical of M.P.E. mechanism [9] : the trap HL 16, created by electron irradiation, has a very small $\sigma_{n}$, not thermally activated, and it would be interesting to measure it with various doping levels in order to search for Auger effect. For the traps EL 5 and EL 11, already at low temperature, $\sigma_{n}$ is in the calculated and extrapolated range of $\sigma_{\infty}$ : there is no thermal activation, and therefore, either there is no lattice relaxation, or it is very large so that in the c.c. diagramm [9] the crossing point of $E_{\mathrm{T}}$ with $E_{\mathrm{C}}$ is at $Q=0$. It is worth noticing that EL 11 looks in that case quite similar to the " $\mathrm{DX}$ " centre [23] existing in GaAlAs layers, but in a very much smaller concentration. This crucial point could be assessed in studying its optical properties.

Acknowledgments. - We are indebted to the L.E.P. epitaxy group for V.P.E. ( $\mathrm{AsCl}_{3} / \mathrm{Ga}$ process) p-type layers, to $\mathrm{J}$. Bourgoin for electron irradiation, and to Dr Woodard of Cornell University (U.S.A.) for providing $n$ and p-type L.P.E. layers.

\section{References}

[1] Lang, D. V., J. Appl. Phys. 45 (1974) 3023.

[2] LaNG, D. V., LogAN, R. A., J. Electron. Mat. 4 (1975) 1053.

[3] Mitonneau, A., Martin, G. M., Mircea, A., Electron. Lett. 13 (1977) 666
[4] Martin, G. M., Mitonneau, A., Mircea, A., Electron. Lett. 13 (1977) 191.

[5] Mircea, A., Bois, D., Int. Conf. on Lattice Defects in Semiconductors, Nice (1978). 
[6] Ikoma, T., Takikawa, M., Okumura, T., Japan. J. Appl. Phys. 16-1 (1977) 223.

[7] Partin, D. L., Minnes, A. G., Vassamillet, L. F., J. Electron. Mat. 7 (1978) 279.

[8] Nelson, R. J., Proc. 7th Int Symp. on GaAs and Related Compounds, St-Louis (1978)

[9] Henry, C. H., Lang, D. V., Phys. Rev. B 13 (1977) 989.

[10] Sekela, A. M., Feucht, D. L., Milnes, A. G., Int. Conf. on GaAs and Rel. Compounds, Deauville, Inst. Phys. Conf. Ser. 5 (1975) 24.

[11] Mircea, A., Mitonneau, A., Appl. Phys. 8 (1975) 15.

[12] Miller, M. D., Olsen, G. H., Ettenberg, M., Appl. Phys. Lett. 31 (1977) 538.

[13] Bois, D., Vincent, G., J. Phys. (F) 38 (1977) L 351.

[14] Williams, R., J. Appl. Phys. 37 (1966) 3411.

[15] Mitonneau, A., Martin, G. M., Mircea, A., Proc. 6th Int. Symp. on $\mathrm{GaAs}$ and related compounds, Edinburgh, sept. 76 (Institute of Physics, London, 33a) 1977.
[16] Mircea, A., Mitonneau, A., Hallais, J., Jaros, M., Phys. Rev. B 16 (1977) 3665.

[17] Zylbersztejn, A., Appl. Phys. Lett. 33 (1978) 200.

[18] Pons, D., Thèse, Paris VI, 1979.

[19] Mitonneau, A., Philips Res. Rep. 31 (1976) 244.

[20] Mircea, A., Mitonneau, A., Vannimenus, J., J. Physique Lett. 38 (1977) L-241.

[21] LaNG, D. V., 1977 Radiation Effects in Semiconductors, 1976 (Inst. Phys. Conf. Ser. 31) 70.

[22] Pons, D., Mircea, A., Mitonneau, A., Martin, G. M., Int. Conf. on Lattice Defects in Semiconductors, Nice (1978).

[23] Lang, D. V., Logan, R. A., Phys. Rev. Lett. 39 (1977) 635

[24] Mitonneau, A., Mircea, A., Submitted to Solid State Commun. 